\title{
Preserving $40 \%$ forest cover is a valuable and well-supported conservation guideline: reply to Banks-Leite et al.
}

Víctor Arroyo-Rodríguez ${ }^{1}$, Lenore Fahrig ${ }^{2}$, James Watling ${ }^{3}$, Justin Nowakowski ${ }^{4}$, Marcelo Tabarelli $^{5}$, Lutz Tischendorf ${ }^{6}$, Felipe Melo ${ }^{5}$, Bráulio Santos ${ }^{7}$, Maira Benchimol ${ }^{6}$, Jose Carlos Morante-Filho ${ }^{8}$, Ferry Slik ${ }^{9}$, Ima Vieira ${ }^{10}$, and Teja Tscharntke ${ }^{11}$

${ }^{1}$ Universidad Nacional Autónoma de México

${ }^{2}$ Carleton University

${ }^{3}$ John Carroll University

${ }^{4}$ Smithsonian Institution

${ }^{5}$ Universidade Federal de Pernambuco

${ }^{6}$ Affiliation not available

${ }^{7}$ Universidade Federal da Paraíba

${ }^{8}$ Universidade Estadual de Santa Cruz

${ }^{9}$ Chinese Academy of Sciences

${ }^{10}$ Museu Paraense Emilio Goeldi

${ }^{11}$ University of Goettingen

December 22, 2020

\begin{abstract}
Banks-Leite et al. (2021) claim that our suggestion of preserving [?]40\% forest cover lacks evidence and can be problematic. We find these claims unfounded, and discuss why conservation planning urgently requires valuable, well-supported, and feasible general guidelines like the $40 \%$ criterion. Using region-specific thresholds worldwide is unfeasible and potentially harmful.
\end{abstract}

Preserving $40 \%$ forest cover is a valuable and well-supported conservation guideline: reply to Banks-Leite et al.

Víctor Arroyo-Rodríguez ${ }^{1,2 *}$, Lenore Fahrig ${ }^{3}$, James I. Watling ${ }^{4}$, Justin Nowakowski ${ }^{5}$, Marcelo Tabarelli ${ }^{6}$, Lutz Tischendorf ${ }^{7}$, Felipe P. L. Melo ${ }^{6}$, Bráulio A. Santos ${ }^{8}$, Maíra Benchimol ${ }^{9}$, Jose Carlos Morante-Filho ${ }^{9}$, J. W. Ferry Slik ${ }^{10}$, Ima C. G. Vieira ${ }^{11}$, and Teja Tscharntke ${ }^{12}$

${ }^{1}$ Instituto de Investigaciones en Ecosistemas y Sustentabilidad, Universidad Nacional Autónoma de México, Morelia 58190, Michoacán, Mexico

${ }^{2}$ Escuela Nacional de Estudios Superiores, Universidad Nacional Autónoma de México, Mérida 97357, Yucatán, Mexico

${ }^{3}$ Geomatics and Landscape Ecology Laboratory, Department of Biology, Carleton University, Ottawa K1S 4B6, Canada

${ }^{4}$ John Carroll University, University Heights, OH 44118, USA

${ }^{5}$ Working Land and Seascapes, Conservation Commons, Smithsonian Institution, Washington, DC 20013, USA 
${ }^{6}$ Departamento de Botânica, Universidade Federal de Pernambuco, Recife, Pernambuco 50670-901, Brazil

${ }^{7}$ ELUTIS Modelling and Consulting Inc., Ottawa, ON K2A 1X4, Canada

${ }^{8}$ Departamento de Sistemática e Ecologia, Universidade Federal da Paraiba, Campus I, João Pessoa, Paraiba 58051-900, Brazil

${ }^{9}$ Laboratório de Ecologia Aplicada à Conservação, Departamento de Ciências Biológicas, Universidade Estadual de Santa Cruz, Ilhéus, Bahia 45662-900, Brazil.

${ }^{10}$ Environmental and Life Sciences, Faculty of Science, Universiti Brunei Darussalam, Gadong BE1410, Brunei Darussalam

${ }^{11}$ Coordenação de Botânica, Museu Paraense Emilio Goeldi, CP 399, Belém, Pará 66040-170, Brazil

${ }^{12}$ Centre of Biodiversity and Sustainable Land Use (CBL), University of Goettingen, Göttingen, Germany

E-mails : VAR (victorarroyo_rodriguez@hotmail.com), LF (lenorefahrig@cunet.carleton.ca), JIW (jwatling@jcu.edu), JN (nowakowskia@si.edu), MT (mtrelli@ufpe.br), LT (lutz.tischendorf@gmx.net), FPLM (fplmelo@gmail.com), BAS (braulio@dse.ufpb.br), MB (mairabs02@gmail.com), JCMF (zemorante@gmail.com), JWFS (ferryslik@hotmail.com), ICGV (ima@museu-goeldi.br), TT (ttschar@gwdg.de)

*Corresponding author : Current address: Escuela Nacional de Estudios Superiores, Universidad Nacional Autónoma de México, Tablaje Catastral no. 6998, Carretera Mérida-Tetiz Km. 4.5, Municipio de Ucú, C.P. 97357, Mérida, Yucatán, Mexico. Phone: +52 (443) 2240894. **ORCID: 0000-0002-0858-0324. ***E-mail: victorarroyo_rodriguez@hotmail.com

Authorship: All authors proposed key points for the response. VAR synthesized them and wrote the first draft, with subsequent changes by all co-authors.

Article type : Technical Comment

Word count : (Abstract: 50) (Main text: 799)

Number of references : 13

Keywords: extinction threshold, general principles, habitat amount, landscape structure, planetary emergency, habitat restoration.

Data accessibility statement : No new data were used.

Novelty statement : Preserving at least $40 \%$ of landscape forest cover is a valuable and useful general principle for biodiversity conservation with enough empirical support. Advocating for using regional-specific thresholds is unuseful and unfeasible given the current planetary emergency.

\begin{abstract}
Banks-Leite et al . (2021) claim that our suggestion of preserving [?]40\% forest cover lacks evidence and can be problematic. We find these claims unfounded, and discuss why conservation planning urgently requires valuable, well-supported, and feasible general guidelines like the $40 \%$ criterion. Using region-specific thresholds worldwide is unfeasible and potentially harmful.
\end{abstract}

\title{
Main text
}

INTRODUCTION

Conservation planning usually combines general principles with site-specific rules (Groom et al . 2005). In our review (Arroyo-Rodriguez et al . 2020), we combined empirically-supported general principles to describe biodiversity-friendly scenarios in human-dominated landscapes. One such principle is based on extinction thresholds: as most species require 10-30\% forest cover in a landscape for population persistence (Andren 
1994; Swift \& Hannon 2010), we suggest that a conservative general guideline would be to maintain [?] $40 \%$ forest cover in landscapes to ensure persistence ofmost forest species (" $40 \%$ criterion" hereafter).

Banks-Leite et al . argued that the $40 \%$ criterion lacks evidence and is problematic, and advocated for using regionally-defined thresholds to guide conservation and restoration. As discussed below, we found their criticisms unfounded, and the idea of basing conservation actions on unique, regionally-defined thresholds impractical and potentially harmful.

\section{VALUE OF THE 40\% CRITERION}

We are in a state of planetary emergency, with forests increasingly lost and degraded by human activities. Therefore, identifying general conservation guidelines such as the $40 \%$ criterion has never been so urgent and valuable. Banks-Leite et al . argue that applying a "fixed" threshold to "any given landscape" is "unhelpful and potentially dangerous" because extinction thresholds vary among species and regions. These claims are misleading, as we specify in our paper that the $40 \%$ criterion is not fixed, and should be adapted to some contexts, such as in tropical regions with low matrix quality (p. 1410 and Fig. 1b in Arroyo-Rodriguez et al . 2020). However, the $40 \%$ criterion is adequate for most species in most landscapes.

Banks-Leite et al . also raised concerns regarding the lack of social and economic considerations in our guidelines. However, the stated aim of our review was to illustrate an optimal human-modified landscape for biodiversity conservation. We agree that alternative scenarios may optimize other outcomes. Ideally, a multicriteria planning process would evaluate tradeoffs among different scenarios (e.g. Neugarten et al . 2016; Vollmer et al . 2016), and we see great potential for future research to inform such planning.

\section{SUPPORT FOR THE $40 \%$ CRITERION}

We disagree that the $40 \%$ criterion lacks evidence. We cited two global reviews of dozens of studies indicating that most species have extinction thresholds at 30\% habitat amount (Andren 1994; Swift \& Hannon 2010). By suggesting $40 \%$ (and not 30\%), we attempt to be more conservative, and compensate for variation and uncertainties associated with the estimation of habitat thresholds (Rompre et al . 2010). Interestingly, two of the studies we 'ignored' also support a 40\% criterion: Macchi et al . (2019) demonstrate that most (71\%) forest birds in the Chaco region have extinction thresholds at $>38 \%$ woody cover, and Melo et al . (2018) found that extinction thresholds average $34 \%$ for birds at tropical latitudes. Although Banks-Leite et al . (2014) found that 30\% forest cover would safeguard Brazilian Atlantic forest vertebrates, other studies in the same biome document higher thresholds for woody plants (40\%, Rigueira et al . 2013) and forest-specialist birds (46\%, Morante-Filho et al . 2015). Therefore, a $40 \%$ general target is more consistent with the evidence than the $30 \%$ preferred by Banks-Leiteet al .

FEASIBILITY OF THE $40 \%$ CRITERION

Banks-Leite et al . suggest that economic constraints in regions requiring massive restoration efforts make the $40 \%$ criterion unfeasible. We disagree. In 50\% of Earth's forested biomes we have already reached the criterion or have sufficient unaltered forest to meet the criterion, and $27 \%$ more biomes have sufficient forest cover to reach the $40 \%$ target with restoration (Dinerstein et al . 2017). In the $23 \%$ of biomes in which forest cover is $<20 \%$ (Dinerstein et al . 2017), we agree that a lower threshold is likely a more feasible target.

Banks-Leite et al . also argue that the $40 \%$ criterion creates confusion among policy makers and undermines public trust in science. This speculation is baseless, as the scientific discussion about extinction thresholds is not under public dispute. We rather suggest the opposite: scientists, as members of society, have a responsibility to inform policy makers and the general public on appropriate use of science in addressing societal issues and concerns (Lees et al . 2020).

\section{ON THE USE OF REGIONALLY-DEFINED THRESHOLDS}

Banks-Leite et al . advocate for regionally-defined thresholds, because we have the "technical capacity " to determine optimal regional forest cover scenarios. We found this suggestion unfeasible and potentially harmful for conservation, as it would require information on extinction thresholds of a wide variety of taxonomic 
groups, each of which will likely have a different threshold. As this information is absent in most regions, we simply do not have the time and resources to identify taxon- and region-specific extinction thresholds across the globe. We agree that, when available, regionally-defined thresholds might be more appealing to decision-makers, but if we insist on using region-specific thresholds everywhere, then deforestation and lack of restoration will continue, and species will go extinct while we spend decades collecting data.

\section{ACKNOWLEDGEMENTS}

BAS thanks the financial support from CNPq (grant number 312178/2019-0).

\section{REFERENCES}

Andren, H. (1994). Effects of habitat fragmentation on birds and mammals in landscapes with different proportions of suitable habitat: a review.Oikos , 71, 355-366.

Arroyo-Rodriguez, V., Fahrig, L., Tabarelli, M., Watling, J.I., Tischendorf, L., Benchimol, M., et al . (2020). Designing optimal human-modified landscapes for forest biodiversity conservation.Ecol. Lett. , 23, 1404-1420

Banks-Leite, C., Pardini, R., Tambosi, L.R., Pearse, W.D., Bueno, A. a, Bruscagin, R.T., et al . (2014). Using ecological thresholds to evaluate the costs and benefits of set-asides in a biodiversity hotspot.Science , 345, 1041-1045.

Dinerstein, E., Olson, D., Joshi, A., Vynne, C., Burgess, N.D., Wikramanayake, E. et al . (2017). An ecoregion-based approach to protecting half the terrestrial realm. Bioscience, 67, 534-545.

Groom, M. J., Meffe, G.K., Carroll, C.R. 2005. Principles of Conservation Biology ( $3^{\text {rd }}$ edition). Sinauer Associates, Inc.

Lees, A.C., Attwood, S., Barlow, J. \& Phalan, B. (2020). Biodiversity scientists must fight the creeping rise of extinction denial. Nat. Ecol. Evol. , 4, 1440-1443.

Macchi, L., Baumann, M., Bluhm, H., Baker, M., Levers, C., Grau, H.R.,et al . (2019). Thresholds in forest bird communities along woody vegetation gradients in the South American Dry Chaco. J. Appl. Ecol. , 56, 629-639

Melo, I., Ochoa-Quintero, J.M., Roque, F. de O. \& Dalsgaard, B. (2018). A review of threshold responses of birds to landscape changes across the world. J. F. Ornithol. , 89, 303-314.

Morante-Filho, J.C., Faria, D., Mariano-Neto, E., \& Rhodes, J. (2015). Birds in anthropogenic landscapes: the responses of ecological groups to forest loss in the Brazilian Atlantic Forest. PLoS One, 10, e0128923.

Neugarten, R.A., Honzak, M., Carret, P., Koenig, K., Andriamaro, L., Cano, C.A., et al . (2016). Rapid assessment of ecosystem service co-benefits of biodiversity priority areas in Madagascar. PloS ONE , 11, e0168575.

Rigueira, D.M.G., da Rocha, P.L.B., \& Mariano-Neto, E. (2013). Forest cover, extinction thresholds and time lags in woody plants (Myrtaceae) in the Brazilian Atlantic Forest: resources for conservation.Biodiv. Conserv. , 22, 3141-3163.

Rompre, G., Boucher, Y., Belanger, L., Cote, S., \& Robinson, W.D. (2010). Conserving biodiversity in managed forest landscapes: the use of critical thresholds for habitat. Forest. Chronicle , 86, 589-596.

Swift, T.L. \& Hannon, S.J. (2010). Critical thresholds associated with habitat loss: A review of the concepts, evidence, and applications.Biol. Rev. , 85, 35-53.

Vollmer, D., Pribadic, D.O., Remondi, F., Rustiadi, E., Gret-Regamey, A. (2016). Prioritizing ecosystem services in rapidly urbanizing river basins: A spatial multi-criteria analaytic approach. Sust. Cities Soc. , $20,237-252$. 